\title{
.
}

\section{6th International Conference on}

\section{Environmental, Agriculture and Rural Development (ICEARD-2022)}

Jan 22-23, 2022

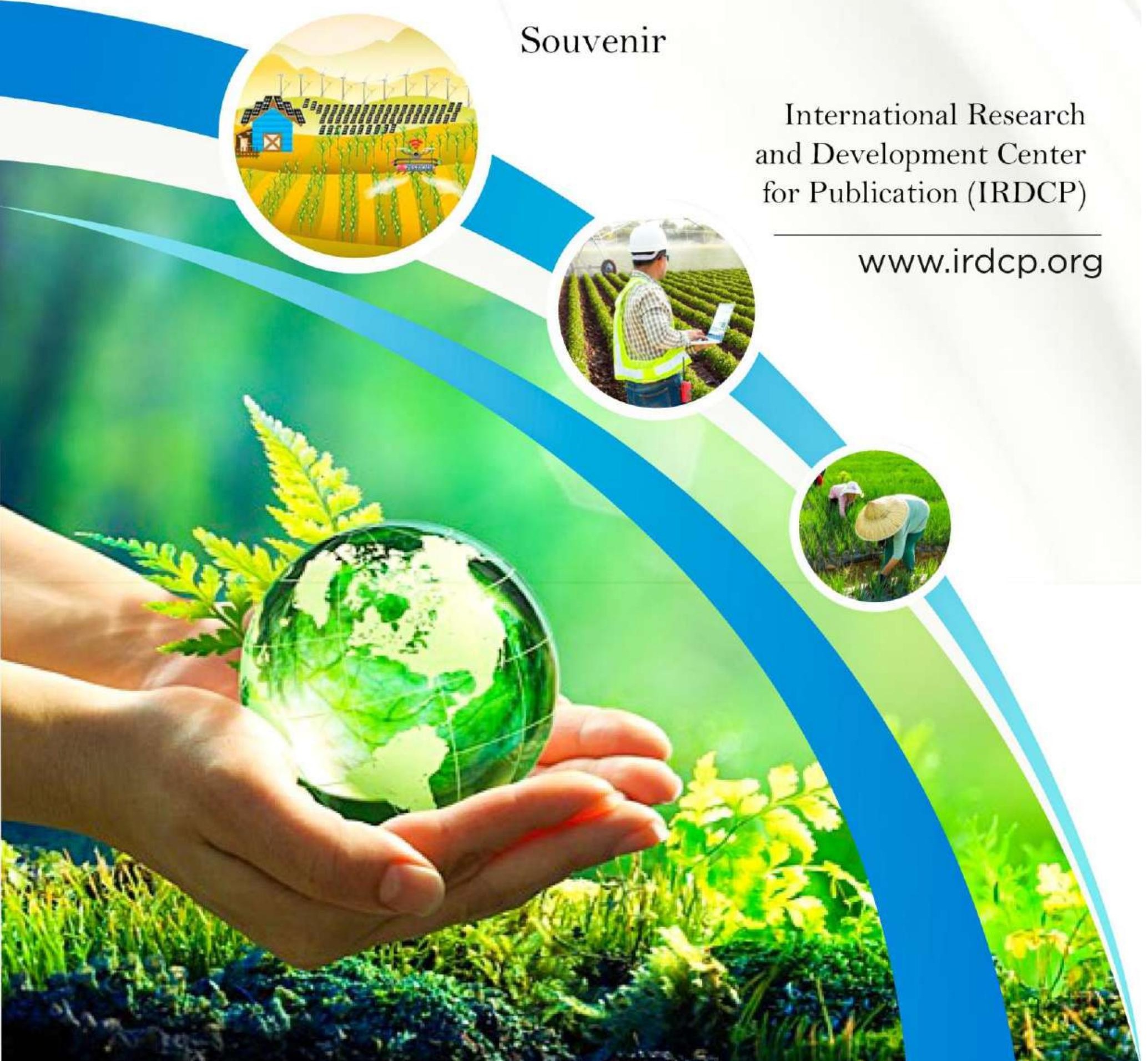




\section{$6^{\text {th }}$ International Conference}

\section{on}

Environmental, Agriculture and Rural Development

$$
\begin{gathered}
\text { (ICEARD-2022) } \\
\text { Jan 22-23, } 2022
\end{gathered}
$$

Copyright (C 20202International Research and Development Center for Publication

DOI: $\underline{10.22161 / \text { conf.eard.jan.2022 }}$

\section{Publisher}

\section{IRDCP}

Email: irdcp.publication@gmail.com |conference.irdcp@gmail.com Web: https://irdcp.org/ 


\section{$\underline{\text { About IRDCP }}$}

International Research and Development Center for Publication (IRDCP) is a nonprofit organization for promoting research and development around the world. IRDCP is the bridge between the quality publisher and researchers. It provides the platform to researchers and academicians for publication in the Scopus Indexed Journals, SCI Journals, Web of Science Journals, UGC Approved Journals, NAAS Rated Journals, Google Scholar Indexed Journals and other good quality DOI journals.

IRDCP is also a partner organization for publication in conference proceedings. We organize the International conferences for publication in SCOPUS indexed and other refereed journals as per the requirement of the authors of the manuscripts. The manuscripts submitted to IRDCP should be plagiarism free and well coherent in all sense.

The scope of publication with the IRDCP covers all type of review and research manuscripts including the Exploratory \& Explanatory Research, Descriptive \& Theoretical Research, Applied Research \& Action Research, Cross-Sectional Research, Quantitative \& Qualitative Research in the field of engineering \& technology, agriculture \& environmental, Social science \& Humanities, Literature \& Education development, Medical \& Health Science.

\section{The vision of IRDCP :}

IRDCP endeavors to promote global excellence in the field of research \& development through diligent applications of advanced technology for the holistic development of society. Also, IRDCP is committed to motivate and persuade the researchers to take up the projects for the continuous development of human society and make this world a better place to live in. The IRDCP has a steadfast commitment be the fulcrum of the ocean of knowledge around which efforts of researchers move about. 


\section{$\underline{\text { About Conference }}$ \\ $\sigma^{\text {th }}$ International Conference on Environmental, Agriculture and Rural Development (EARD-2022)}

During the worldwide lockdown due to COVID 19 pandemic, a lot of important activities have come to a halt. However, when we look at the brighter side, all of us have more time for adding to our knowledge and insights.

With this aim, to keep contributing to learning and motivation International research and development Center for publication is going to organize a two-day International Conference with the title " 6th International Conference on Environmental, Agriculture and Rural Development (EARD-2022)" on Jan 22-23, 2022.

We hope, this online mode of the conference in COVID-19 pandemic will be an appreciable step in promoting the research activities and new information between researchers, developers, students, academicians and practitioners working in and around the world by keeping the social distance in view to stop the spread of COVID-19 disease. This conference aims is to present the current researches being carried out in the field of social science and education development around the globe.

Prospective authors from academia as well as industry are invited to submit their abstracts that illustrate original/unpublished works and industrial applications describing advances and significant innovations in the field. 


\section{International Advisory Committee}

- Muvunyi Ronaldo, Taiyuan University of Technology, China

- Sahar Mirzaei, Horticultural Science Research Institute, Agricultural Research, Education and Extension Organization (AREEO), Mahallat, Iran.

- Professor Tamuno-Omi Godwin Dappa, Federal University Wukari, Nigeria

- Dr. Etim Nse Akpan, Federal University Wukari, Nigeria

- Dr. Elechi Felix Aja, Ebonyi State University, Abakaliki, Nigeria

- Dr. Mehmet Firat Baran, Associate Prof. , Faculty of Technology, Department of Energy Systems Engineering, Altinsehir, Adiyaman, Turkey

- Dr. Alexandra D. Solomou, Agricultural Engineer, Hellenic Agricultural Organization "DEMETER", Institute of Mediterranean and Forest Ecosystems, Terma Alkmanos, Ilisia, 11528, Athens, Greece.

- Dr. A. Heidari, Faculty of Chemistry, California South University (CSU), Irvine, California, USA

- Dr. Abd El-Aleem Saad Soliman Desoky, Faculty of Agriculture, Sohag University, Egypt

- Dr. Ekrem BÖLÜKBAŞI, Molecular biology and Biotechnology, Amasya University, Turkey

- Assoc. Prof Dr. Mehmet Karakaş, General biology and zoology, Physiology, Ankara University, Turkey 


\section{Message}

I am extremely pleased to share that International Research and Development Center for Publication (IRDCP) is organizing a two days " 6th International Conference on Environmental, Agriculture and Rural Development (EARD-2022)" on Jan 22-23, 2022.

I am sure the state of art lectures from the invited experts and the research findings of researchers, academicians, utility engineers will enrich the knowledge of all the participants. It will provide an excellent opportunity for students to learn new ideas.

I offer my best wishes to the whole team of the organizing committee, the participants, and volunteers for the grand success of the conference.

Dr. Kiran

Convenor EARD-2022 


\section{Message}

I am happy to know that International Research and Development Center for Publication (IRDCP) is organizing a two days " 6th International Conference on Environmental, Agriculture and Rural Development (EARD-2022)" on Jan 22-23, 2022 on Oct 17-18, 2020. I am sure that, this conference would provide an ideal platform for the academicians, scholars and experts to present and exchange their research findings and Ideas.

I wish the conference a great success.

Dr. Praveen Kumar Jain 

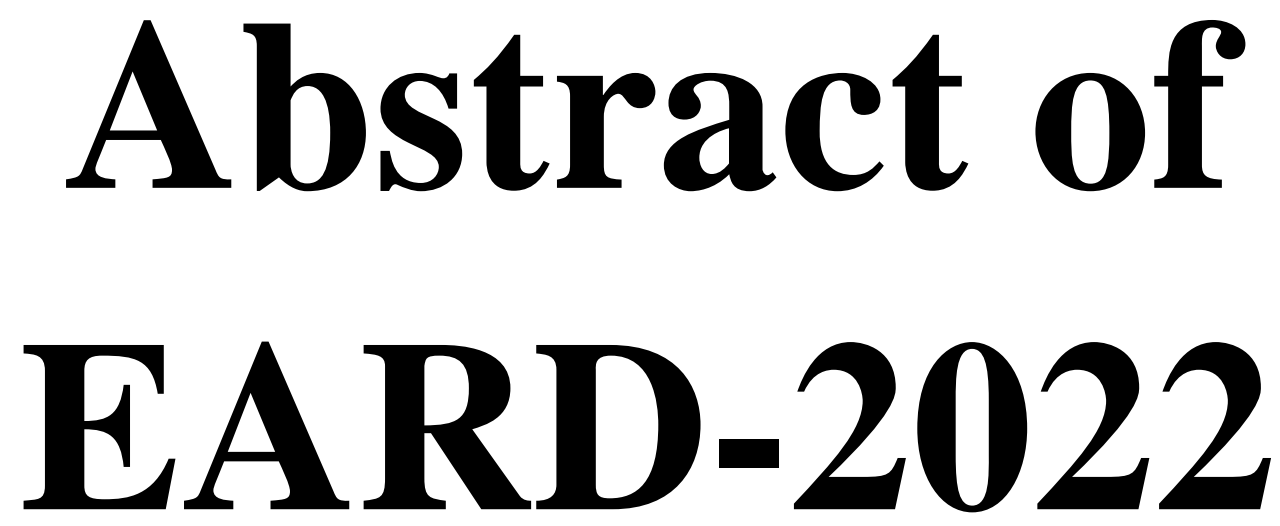


\title{
Ecosystem Capacity Assessment based on Ecological Connectivity of the Urban Green Infrastructure: Biodiversity Reservoirs Role in Carbon Sequestration
}

\author{
Delloul Sabri, Naimi Ait-Aoudia Meriem \\ ETAP Research Laboratory, Institute of Architecture and Urbanism, University of Blida 1, \\ Blida, Algeria \\ Email Id: sabridelloul@etu.univ-blida.dz
}

\begin{abstract}
Vegetation system is of importance for storing carbon in green urban areas. The consideration of this process of carbon sequestration as an ecosystem service dates to 2009 following to works of Piao and his associates on urban vegetation and carbon cycles in cities. However, the acceleration of urban growth in most of cities in Algeria at the expense of large landscapes and natural settings has led to a huge impact on urban climate change and increases greenhouse gas emissions. To address this issue, the Amar Benaouda new city located in the county of Annaba, constitutes an unprecedented project of green city in Algeria. With a ratio of $27 \%$ intended for green spaces, the new project clearly reflects the political will to implement urban ecology in Algerian cities. The objective of this paper is to quantify the contribution of the urban green infrastructure of Amar Benaouda city in carbon sequestration according to quality of its ecological connectivity state. For this purpose, this study mobilizes methods of selecting morphological assessment indicators of carbon sequestration in the three grid structures of the studied city namely: Biodiversity Reservoirs, Ecological Corridors and Eco-landscape Matrix. In addition, the geographic information system (GIS) is used to map and to combine different data. Mains obtained results highlight the role of biodiversity reservoirs and confirm the proportionality between the carbon absorption capacity and density of urban vegetation. This method provides a tool to help leaders optimizing urban planning and design of the new city's green infrastructure.
\end{abstract}

Keywords - assessment by indicators, biodiversity reservoirs, carbon sequestration, ecological connectivity, urban green infrastructure

\section{References:}

[1] Bhan, M., Gingrich, S., Matej, S., Fritz, S., \& Erb, K.-H. (2021). Land Use Increases the Correlation between Tree Cover and Biomass Carbon Stocks in the Global Tropics. Land 2021, Vol. 10, Page 1217, 10(11), 1217. https://doi.org/10.3390/LAND10111217

[2] Eloka-Eboka, A. C., Bwapwa, J. K., \& Maroa, S. (2020). Biomass for CO2 Sequestration. Encyclopedia of Renewable and Sustainable Materials, 277-290. https://doi.org/10.1016/B978-0-12-803581-8.11029-X

[3] Farinha, M. J. U. S., Berezuk, A. G., \& Bernardo, L. V. M. (2021). Green areas in an urban area and provision of ecosystem services: a bibliometric and integrative review. 
Revista Em Agronegócio e Meio Ambiente, 14(Supl. 2), 1-15. https://doi.org/10.17765/2176-9168.2021V14SUPL.2.E9628

[4] Guo, X., \& Fang, C. (2021). Integrated Land Use Change Related Carbon Source/Sink Examination in Jiangsu Province. Land 2021, Vol. 10, Page 1310, 10(12), 1310. https://doi.org/10.3390/LAND10121310

[5] Wang, J., Rienow, A., David, M., \& Albert, C. (2022). Green infrastructure connectivity analysis across spatiotemporal scales: A transferable approach in the Ruhr Metropolitan Area, Germany. Science of The Total Environment, 813, 152463. https://doi.org/10.1016/J.SCITOTENV.2021.152463

[6] Wang, Y., Chang, Q., \& Li, X. (2021). Promoting sustainable carbon sequestration of plants in urban greenspace by planting design: A case study in parks of Beijing. Urban Forestry \& Urban Greening, 64, 127291. https://doi.org/10.1016/J.UFUG.2021.127291

[7] Wang, Z., Xu, L., Shi, Y., Ma, Q., Wu, Y., Lu, Z., ... Zhang, Q. (2021). Impact of Land Use Change on Vegetation Carbon Storage During Rapid Urbanization: A Case Study of Hangzhou, China. Chinese Geographical Science 2021 31:2, 31(2), 209-222. https://doi.org/10.1007/S11769-021-1183-Y

[8] Xu, Y.-C., Li, X.-H., Ren, K., \& Chai, L.-H. (2020). Structures of urban carbon cycle based on network indicators: Cases of typical cities in China. Journal of Cleaner Production, 282, 125405. https://doi.org/https://doi.org/10.1016/j.jclepro.2020.125405 


\title{
Impact of Polystyrene Microplastic Contaminated Environment on Reproduction of Physa acuta
}

\author{
Nisha Kumari*, Ram Kumar, Devesh Kumar Yadav
}

\begin{abstract}
Ecosystem Research Laboratory, Department of Environmental Science School of Earth, Biological and Environmental Sciences, Central University of South Bihar, SH-7, GayaPanchanpur Rd, Fatehpur, Gaya-Bihar 824236, India
\end{abstract}

Email Id: nishakumari@cusb.ac.in

\begin{abstract}
Today microplastic have been explored in ocean, rivers, estuaries and lake globally, appraising their consequences on biota has become an important research preference.Physa acuta a fresh water benthic organism is Native of North America but an invasive species in Indian fresh water ecosystem. Found in benthic zone in all type of freshwater ecosystem. Due to its abundance in fresh water ecosystem, this study aims to determine the effect of polystyrene microplastic $(32.0 \mu \mathrm{m}-20.0 \mu \mathrm{m}$ size range) on reproduction rate and hatching success on freshwater benthic macroinvertebrate (Physa acuta) using microplastic concentration $9 \mathrm{mg} / 200 \mathrm{ml}$ and control (without microplastic). We observed egg capsule production for consecutive 93 days and hatching success. Egg capsule produced daily were counted manually twice in a day for 93 days to assess the reproduction rate. Number of eggs in an egg capsule was also counted daily. Negative impact of polystyrene microplastic was observed in reproduction rate. Hatching success were also negatively affected in polystyrene microplastic contaminated environment. Microplastic caused negative effect on the survival, reproduction rate and hatching success of Physa acuta. Physa acuta is an invasive species however the negative impact of polystyrene microplastic at concentration $9 \mathrm{mg} / 200 \mathrm{ml}$ is seen on reproduction rate and on survival, the microplastic at this concentration may affect the native species even more prominently.
\end{abstract}

Keywords- Freshwater ecosystem, microplastic, Physa acuta, Polystyrene, reproduction 